\title{
Hidratação controlada de sementes de pinhão manso ${ }^{1}$
}

\author{
Controlled hydration of jatropha seeds
}

\author{
Nathália da Silva Braga², Camila Santos Barros de Morais $^{3}$ e Claudia Antonia Vieira Rossetto ${ }^{4 *}$
}

RESUMO - A hidratação controlada pode favorecer a germinação e o estabelecimento das plantas de diversas espécies. O objetivo desse trabalho foi avaliar o efeito do condicionamento fisiológico pela técnica da hidratação controlada seguida de secagem na qualidade fisiológica e no estabelecimento de plantas de pinhão manso. Por lote, foi estabelecida a curva de absorção de água pelas sementes. Posteriormente, as sementes foram imersas em água destilada $\left(8 \mathrm{~mL} \mathrm{~g}^{-1}\right)$, secas a $32{ }^{\circ} \mathrm{C}$ até atingir teor de água próximo ao inicial e submetidas aos testes de germinação e de vigor (primeira contagem, classificação de plântulas e emergência de plântulas em areia). Em casa de vegetação, as sementes foram distribuídas entre substrato plantmax. De acordo com resultados pode-se concluir que a hidratação promoveu o aumento do comprimento e da massa seca de plântulas e favoreceu a emergência de plântulas de pinhão manso. A sobrevivência das plantas provenientes apenas de sementes de qualidade fisiológica intermediária é beneficiada pela hidratação das sementes de pinhão manso.

Palavras-chave: Jathorpha curcas L. Plantas e água. Germinação.

\begin{abstract}
Controlled hydration can promote the germination and establishment of the plants of various species. The aim of this study was to evaluate the effect of priming, using a technique of controlled hydration followed by drying, on the physiological attributes and establishment of jatropha plants. The water-absorption curve was established per batch of seeds. Subsequently, the seeds were immersed in distilled water $\left(8 \mathrm{~mL} \mathrm{~g}^{-1}\right)$, dried at $32{ }^{\circ} \mathrm{C}$ until a water content close to the initial levels was reached, and subjected to tests for germination and vigor (initial counting, seedling classification, and the emergence of seedlings in sand). In the greenhouse, seeds were distributed in a plantmax substrate. From the results it can be concluded that hydration promotes an increase in the length and dry matter of seedlings, and favors the emergence of Jatropha seedlings. The survival of plants from seeds with only intermediate physiological attributes, benefits from the hydration of Jatropha seeds.
\end{abstract}

Key words: Jathorpha curcas L. Plants and water. Germination.

\footnotetext{
*Autor para correspondência

${ }^{1}$ Recebido para publicação em 08/02/2011; aprovado 28/02/2012

Parte da Dissertação de Mestrado do primeiro autor, apresentado ao curso de Pós-Graduação em Fitotecnia/UFRRJ

${ }^{2}$ Pós-Graduação em Fitotecnia/Universidade Federal Rural do Rio de Janeiro, Seropédica-RJ, Brasil, anathbraga@yahoo.com.br

${ }^{3}$ Pós-Graduação em Fitotecnia/Universidade Federal Rural do Rio de Janeiro, Seropédica-RJ, Brasil, sbcamila@ yahoo.com.br

${ }^{4}$ Departamento de Fitotecnia/Universidade Federal Rural do Rio de Janeiro, BR 467, Km 07, Seropédica-RJ, Brasil, 23.890-000, cavrosse@ ufrrj.br
} 


\section{INTRODUÇÃO}

O pinhão manso (Jatropha curcas L.) tem demonstrado potencial como matéria prima destinada à produção de biodiesel (DRUMOND, 2010). No entanto, faltam conhecimentos relacionados à implantação e condução desta cultura (CHAVES et al., 2009). Para o estabelecimento das plantas no campo são necessárias sementes vigorosas, capazes de germinar rápida e uniformemente. Para isto, vem sendo aplicados vários tratamentos de pré-semeadura denominados de condicionamento fisiológico (MARCOS FILHO, 2005). Dentre eles, a técnica de hidratação controlada seguida por secagem tem mostrado resultados satisfatórios para varias espécies (BRAZ; ROSSETTO, 2008; FAROOQ et al., 2010; GHASSEMI-GOLEZANI et al., 2010). Esta técnica, alem de ser simples e não empregar reagentes ou equipamentos sofisticados, permite o reparo metabólico das sementes durante o processo de hidratação, o que reduz os níveis de deterioração e favorece o processo de germinação (HARRIS et al., 2001).

Os benefícios do condicionamento fisiológico têm sido atribuídos à adaptação das plantas às condições de estresses climáticos, bem como a superação de dormência das sementes e à ativação prévia da atividade metabólica, através do estímulo da atividade das enzimas removedoras de radicais livres, favorecendo o processo germinativo (BAILLY et al., 2002; SANCHEZ; ORTA; MUNOZ, 2001).

Em oleaginosas, Hussain et al. (2006) verificaram que a imersão de sementes de girassol durante 24 horas a $27^{\circ} \mathrm{C}$ seguida de secagem promoveu aumento na velocidade de emergência das plântulas em condições de campo. Para soja, a imersão em água durante 12 horas a $25{ }^{\circ} \mathrm{C}$, seguida de secagem, e imersão em solução de auxina e giberelina favoreceram a emergência de plântulas e o comprimento das folhas (BEJANDI et al., 2009). Fujikura et al. (1993) constataram que em sementes de girassol, a imersão em água por cinco horas a $23{ }^{\circ} \mathrm{C}$ seguida de secagem a $20{ }^{\circ} \mathrm{C}$ favoreceu a porcentagem de plântulas normais a 20 e $30{ }^{\circ} \mathrm{C}$. Já, em algodão, a imersão em água durante 15 horas seguida de secagem proporcionou aumento da germinação, tanto quanto a imersão em soluções com -1,2 MPa (RIBEIRO et al., 2002). Em pinhão manso, Pinto et al. (2009) constataram que a imersão em água visando atingir $40 \%$ de água nas sementes apresentou aumento na porcentagem de sementes viáveis avaliadas pelo teste de tetrazólio. Em outras espécies também tem sido encontrados resultados favoráveis desta técnica na germinação (BRAZ; ROSSETTO, 2008; CASEIRO; BENNETT; MARCOS FILHO., 2004) e no período médio de germinação de sementes envelhecidas (THORNTON; POWELL, 1995).

Outro aspecto a abordar é o estudo do comportamento da embebição e da fase inicial da germinação visando determinar o período de imersão das sementes durante o tratamento de hidratação. A velocidade de absorção de água é condicionada por vários fatores. Dentre eles, sementes com menor permeabilidade do tegumento, bem como menor conteúdo de água e menor desempenho fisiológico (BORTOLOTTO et al., 2008; MARCOS FILHO, 2005); absorvem mais lentamente a água. Para Bewley e Black (1994), a embebição segue um padrão trifásico. Em sementes de outras oleaginosas, também vem sendo observado o padrão trifásico de absorção de água, tais como em soja (ROSSETTO et al., 1997) e girassol (CONCENÇO et al., 2007). Dentro do contexto, o objetivo desse trabalho foi avaliar o efeito do condicionamento fisiológico pela técnica da hidratação controlada seguida de secagem na qualidade fisiológica e no estabelecimento de plantas de pinhão manso.

\section{MATERIAL E MÉTODOS}

Foram utilizados cinco lotes de sementes de pinhão manso, colhidos em janeiro de 2008, sendo quatro provenientes de cultivo comercial da empresa NNE Minas (lotes $1 ; 2 ; 3$ e 4) e um lote proveniente da Coordenadoria de Assistência Técnica Integral -CATI (lote 5). As sementes apresentavam 6,7 a 7,7\% de água, massa média de 1.000 sementes entre 680,38 e 730,29 g e $90 \%$ destas foram retidas pela peneira com crivo circular de diâmetro de 11/64" e de 10/64" de polegada. Após o recebimento dos cinco lotes, as sementes foram armazenadas por dois meses em condições de umidade relativa do ar de $45 \%$ e temperatura de $18 \pm 2{ }^{\circ} \mathrm{C}$.

Primeiramente foi estabelecida a curva de absorção de água pelas sementes. Para isto, foi utilizado o delineamento experimental inteiramente casualizado em esquema fatorial (cinco lotes $\mathrm{x}$ cinco períodos de embebição). Quatro subamostras de 25 sementes por lote (aproximadamente 13,0 g) foram previamente pesadas e imersas em água destilada $\left(8 \mathrm{~mL} \mathrm{~g}^{-1}\right)$, em sistema aerado, sob $20{ }^{\circ} \mathrm{C}$, em ausência de luz, com base em Braz e Rossetto (2008). A avaliação da absorção de água pelas sementes, realizada separadamente por lote, foi efetuada mediante pesagens. Para tanto, as sementes foram retiradas do germinador, após 24; 48; 96; 144 e 192 horas, ou seja, até que fosse observada a emissão da raiz primária. Em cada avaliação, foi realizado o calculo do teor de água das sementes, considerando o teor inicial de água e a massa de matéria seca. Os resultados foram expressos em porcentagem de água atingida pelas sementes em cada período de embebição.

Para avaliação do efeito da hidratação controlada seguida de secagem na qualidade fisiológica das sementes, foi utilizado o delineamento experimental inteiramente 
casualizado em esquema fatorial (cinco lotes $\mathrm{x}$ dois tratamentos de hidratação), com quatro repetições. Para isto, quatro subamostras de 25 sementes por lote foram ou não hidratadas por meio da imersão em água destilada, em sistema aerado, sob $20^{\circ} \mathrm{C}$, na ausência de luz. Após o período de embebição, as sementes foram submetidas à determinação do grau de umidade e, em seguida, secas em estufa com circulação de ar forçada a $30 \pm 2{ }^{\circ} \mathrm{C}$ (BARROS; ROSSETTO, 2009) até que estas atingissem o teor de água próximo ao inicial, sendo submetidas novamente à determinação do grau de umidade e a avaliação da qualidade fisiológica.

O grau de umidade foi determinado pelo método de estufa a $105^{\circ} \mathrm{C} \pm 3$ por 24 horas, com quatro subamostras de 25 sementes, por lote, com base em recomendações para manoma (Ricinus communis L.) com base em Brasil (2009). Os resultados foram expressos em porcentagem. O teste de germinação foi conduzido com quatro subamostras de 25 sementes, por lote, distribuídas em rolos de papel germitest, umedecidos com água destilada, na proporção de 2,5 vezes a sua massa seca e mantidas a $30{ }^{\circ} \mathrm{C}$ na ausência de luz. As avaliações foram efetuadas aos sete e 14 dias, sendo consideradas normais as plântulas sadias e bem desenvolvidas (BRASIL, 2009). Plântulas consideradas pouco desenvolvidas (deformadas) ou apresentando deterioração total ou parcial de estruturas (deterioradas) foram classificadas como anormais. As sementes não germinadas foram aquelas consideradas mortas e duras. Os resultados foram expressos em porcentagem. Em conjunto com o teste de germinação, foi considerada a porcentagem de plântulas normais obtida na primeira contagem, com base em Nakagawa (1994). Os resultados foram expressos em porcentagem. O teste de comprimento de plântulas foi realizado com quatro subamostras de 10 sementes, por lote. A condução do teste foi de maneira semelhante a do teste de germinação. No entanto, somente após 14 dias da instalação, foi feita a avaliação do comprimento (total, raiz primária e hipocótilo) e da massa de matéria seca por plântula (após 24 horas em estufa a $80^{\circ} \mathrm{C}$ ), com base em Nakagawa (1994). Os valores foram expressos em mg plântula ${ }^{-1}$.O teste de emergência de plântulas em areia foi realizado com quatro subamostras de 25 sementes, por lote, semeadas a $0,5 \mathrm{~cm}$ de profundidade em caixas plásticas, contendo $7 \mathrm{~kg}$ por caixa de areia lavada, esterilizada (autoclave a $120{ }^{\circ} \mathrm{C}$ ) e umedecida com água destilada na proporção recomendada em Brasil (2009). Os resultados foram expressos em porcentagem. Em conjunto, foi calculado o índice de velocidade de emergência (IVE). As avaliações foram realizadas durante 13 dias, com base em Nakagawa (1994).

Para a avaliação da hidratação no estabelecimento das plantas destinadas a propagação, as sementes foram distribuídas em sacos plásticos ( 10 x 20) contendo substrato comercial (plantamax) e mantidas em casa de vegetação. Para isto, foi avaliada a porcentagem de sobrevivência, a altura, o número de folhas e o diâmetro do caule das plantas, aos 10; 20; 30 e 40 dias após a instalação.
Com bases nos resultados dos testes de Lilliefors e de Cochran e Bartley, não foi necessária a transformação dos dados. Posteriormente, foram realizadas as análises de variância. Nos fatores qualitativos, as médias foram comparadas pelo teste de Tukey $(\mathrm{p}=0,05)$. No fator quantitativo, quando houve significância entre os tratamentos foi realizada a análise de regressão. As equações foram analisadas e selecionadas com base no coeficiente de determinação, na significância do teste $\mathrm{t}$ de Student ao nível de $5 \%$ de probabilidade do erro e na expectativa biológica.

\section{RESULTADOS E DISCUSSÃO}

A porcentagem de água nas sementes de pinhão manso após a embebição variou em função da interação entre os lotes avaliados e os períodos de exposição (Tabela 1). Assim, a maior porcentagem de água absorvida foi constatada nas sementes dos lotes 1 e 4, após 48; 96; 144 e 192 horas (Tabela 2), provavelmente, em função da maior qualidade fisiológica destas sementes. Estes dados concordam com Bortolotto et al. (2008), que mencionam que sementes com maior desempenho fisiológico absorvem água mais rapidamente.

Na Figura 1 foi verificado que até 24 horas de embebição houve acentuada absorção de água pelas sementes dos cinco lotes. Após 192 horas de embebição, apenas as sementes dos lotes 2 e 4, 46,0 e 47,8\%, respectivamente, emitiram a raiz primária (dados não apresentados), que é considerado como o inicio da fase III da curva de absorção de água proposta por Bewley e Black (1994).

A porcentagem de plântulas normais na primeira contagem bem como a porcentagem de germinação e de sementes não germinadas variou em função da interação entre os lotes avaliados e os tratamentos de hidratação a que foram submetidas (Tabela 3). Assim, quando foi realizada hidratação das sementes, foi constatado que este tratamento favoreceu a germinação das sementes dos lotes 2; 3 e 4 (Tabela 4). Estes resultados foram

Tabela 1- Resumo da análise de variância para os dados de porcentagem de água absorvida pelas sementes de pinhão manso

\begin{tabular}{lcc}
\hline \multicolumn{1}{c}{ Fontes de variação } & GL & Valores de F \\
\hline Repetição & 3 & $0,14^{\mathrm{ns}}$ \\
Lotes & 4 & $32,02^{* *}$ \\
Períodos & 5 & $5599,95^{* *}$ \\
Lotes x Períodos & 20 & $2,06^{* *}$ \\
Resíduo & 87 & - \\
C.V. $(\%)$ & & 2,37 \\
ns - não significativo, **- significativo a $1 \%$ e *- significativo a 5\% \\
pelo teste F
\end{tabular}


Tabela 2 - Dados médios, em porcentagem, de água de cinco lotes de sementes de pinhão manso, em função do período de embebição

\begin{tabular}{ccccccc}
\hline \multirow{2}{*}{ Período } & \multicolumn{7}{c}{ Teor de água $(\%)$} \\
\cline { 2 - 7 } & Lote 1 & Lote 2 & Lote 3 & Lote 4 & Lote 5 & \multicolumn{1}{c}{ Médias } \\
\hline 0 & $8,2 \mathrm{~A}$ & $7,3 \mathrm{~A}$ & $7,8 \mathrm{~A}$ & $6,8 \mathrm{~A}$ & $7,5 \mathrm{~A}$ & 7,5 \\
24 & $43,8 \mathrm{~A}$ & $41,8 \mathrm{~B}$ & $43,9 \mathrm{~A}$ & $43,8 \mathrm{~A}$ & $41,5 \mathrm{~B}$ & 43,0 \\
48 & $46,5 \mathrm{~A}$ & $44,3 \mathrm{~B}$ & $46,0 \mathrm{AB}$ & $46,5 \mathrm{~A}$ & $42,0 \mathrm{C}$ & 45,1 \\
96 & $46,9 \mathrm{~A}$ & $44,8 \mathrm{BC}$ & $46,4 \mathrm{AB}$ & $46,9 \mathrm{~A}$ & $44,3 \mathrm{C}$ & 45,9 \\
144 & $47,1 \mathrm{~A}$ & $45,0 \mathrm{BC}$ & $46,8 \mathrm{AB}$ & $47,3 \mathrm{~A}$ & $44,4 \mathrm{C}$ & 46,1 \\
192 & $47,9 \mathrm{~A}$ & $46,0 \mathrm{BC}$ & $47,3 \mathrm{AB}$ & $47,7 \mathrm{~A}$ & $44,7 \mathrm{C}$ & 46,6 \\
Médias & 40,12 & 38,23 & 39,75 & 39,89 & 37,45 & \\
\hline
\end{tabular}

*Médias seguidas da mesma letra maiúscula na linha, não diferem entre si pelo teste de Tukey a p >0,5

Figura 1 - Dados médios, em porcentagem, de água absorvida pelas sementes de cinco lotes $(1(\bullet), 2(\mathrm{O}), 3(\boldsymbol{\nabla}), 4(\Delta)$ e $5(\bullet))$ de pinhão manso, obtidos após terem sido imersas em água a $20^{\circ} \mathrm{C}$, em função do período de embebição

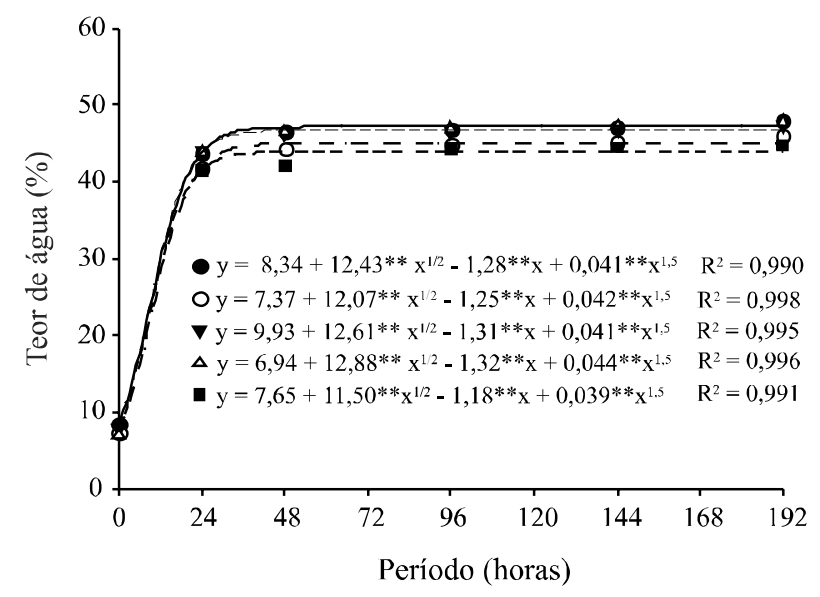

**- significativo a $1 \%$ pelo teste $\mathrm{F}$ semelhantes aos encontrados por Fujikura et al. (1993), Ribeiro et al. (2002) e Giurizatto et al. (2008), que observaram efeito favorável da imersão em água seguida de secagem na germinação de sementes de girassol, algodão e soja, respectivamente. Já, para os lotes 1 e 5 não houve diferenças significativas entre os tratamentos (com e sem hidratação) quanto a germinação (Tabela 4). Quando comparou-se os lotes sem a realização da hidratação, foi observado maior porcentagem de germinação das sementes dos lotes 1; 2 e 4 (Tabela 4). Na avaliação do tratamento de hidratação, a maior germinação e a menor porcentagem de sementes não germinadas foi constatado no lotes 4 (Tabela 4). O valor da porcentagem de germinação deste lote assim como o do lote 2 foi maior que $80 \%$ de germinação (Tabela 4), o que permite a comercialização com base nos padrões estabelecidos para as sementes de outras oleaginosas (BRASIL, 2005). Para girassol e algodão estes valores devem ser superiores a $70 \%$ e para mamona, a $80 \%$.

Tabela 3 - Resumo da análise de variância para os dados de plântulas normais na primeira contagem de germinação (PC), de germinação (G), de plântulas anormais (deformadas (PAD), deterioradas (PADT), totais (PAT)) e de sementes não germinadas (SNG), obtidos de cinco lotes de sementes de pinhão manso após terem sido ou não submetidas à técnica de hidratação por imersão em água

\begin{tabular}{lccccccc}
\hline & & \multicolumn{7}{c}{ Quadrado Médio } \\
\cline { 3 - 8 } Fontes de variação & GL & G & PC & PAD & PADT & PAT & SNG \\
\hline Lotes $(\mathrm{L})$ & 4 & $2162,600^{* *}$ & $2278,600^{* *}$ & $12,668^{* *}$ & $3,040^{* *}$ & $9,639^{* *}$ & $14,471^{* *}$ \\
Hidratação(H) & 1 & $883,600^{* *}$ & $2496,400^{* *}$ & $0,047^{* *}$ & $17,875^{* *}$ & $11,796^{* *}$ & $0,746^{\text {ns }}$ \\
L x H & 4 & $112,600^{*}$ & $201,400^{* *}$ & $0,735^{\text {ns }}$ & $1,901^{\text {ns }}$ & $0,823^{\text {ns }}$ & $4,572^{* *}$ \\
Erro & 30 & 34,000 & 37,200 & 1,156 & 0,895 & 1,024 & 0,557 \\
C.V. $(\%)$ & & 8,88 & 10,57 & 53,82 & 32,10 & 27,66 & 17,39 \\
\hline
\end{tabular}

ns-não significativo, *-significativo a $5 \%$ pelo teste $\mathrm{Fe}$ **- significativo a $1 \%$ pelo teste $\mathrm{F}$ 
Tabela 4 - Dados médios de plântulas normais na primeira contagem de germinação, de germinação, de plântulas anormais (deformadas, deterioradas, totais) e de sementes não germinadas, obtidos de cinco lotes de sementes de pinhão manso após terem sido ou não submetidas à técnica de hidratação por imersão em água

\begin{tabular}{|c|c|c|c|c|c|c|}
\hline \multirow{2}{*}{ Lotes } & Sem hidratação & Com hidratação & Médias & Sem hidratação & Com hidratação & Médias \\
\hline & \multicolumn{3}{|c|}{ Primeira Contagem $(\%)$} & \multicolumn{3}{|c|}{ Germinação (\%) } \\
\hline 1 & $58 \mathrm{Aa}^{*}$ & $61 \mathrm{Ac}$ & 60 & $67 \mathrm{Aab}$ & $65 \mathrm{Ac}$ & 66 \\
\hline 2 & $57 \mathrm{Bab}$ & $74 \mathrm{Ab}$ & 66 & $70 \mathrm{Ba}$ & $81 \mathrm{Ab}$ & 76 \\
\hline 3 & $26 \mathrm{Bc}$ & $40 \mathrm{Ad}$ & 33 & $35 \mathrm{Bd}$ & $48 \mathrm{Ad}$ & 42 \\
\hline 4 & $63 \mathrm{Ba}$ & $94 \mathrm{Aa}$ & 79 & $76 \mathrm{Ba}$ & $94 \mathrm{Aa}$ & 85 \\
\hline 5 & $45 \mathrm{Bb}$ & $59 \mathrm{Ac}$ & 52 & $57 \mathrm{Ac}$ & $64 \mathrm{Ac}$ & 61 \\
\hline \multirow[t]{2}{*}{ Médias } & 50 & 66 & 58 & 61 & 70 & 66 \\
\hline & \multicolumn{3}{|c|}{ Plântulas anormais deterioradas (\%) } & \multicolumn{3}{|c|}{ Plântulas anormais deformadas (\%) } \\
\hline 1 & 0 & 1 & 1 & 21 & 8 & 15 \\
\hline 2 & 1 & 0 & 1 & 13 & 4 & 9 \\
\hline 3 & 19 & 17 & 18 & 15 & 8 & 12 \\
\hline 4 & 2 & 6 & 4 & 11 & 0 & 6 \\
\hline 5 & 5 & 1 & 3 & 6 & 7 & 7 \\
\hline \multirow[t]{2}{*}{ Médias } & $5 \mathrm{~A}$ & $5 \mathrm{~A}$ & 5 & $13 \mathrm{~A}$ & $5 \mathrm{~B}$ & 9 \\
\hline & \multicolumn{3}{|c|}{ Plântulas anormais totais (\%) } & \multicolumn{3}{|c|}{ Sementes não germinadas $(\%)$} \\
\hline 1 & 21 & 9 & $15 \mathrm{~b}$ & $12 \mathrm{Bb}$ & $26 \mathrm{Aa}$ & 19 \\
\hline 2 & 14 & 4 & $9 \mathrm{~b}$ & $16 \mathrm{Ab}$ & $15 \mathrm{Aa}$ & 16 \\
\hline 3 & 34 & 25 & $30 \mathrm{a}$ & $31 \mathrm{Aa}$ & $27 \mathrm{Aa}$ & 29 \\
\hline 4 & 13 & 6 & $10 \mathrm{~b}$ & $11 \mathrm{Ab}$ & $0 \mathrm{Bb}$ & 6 \\
\hline 5 & 11 & 8 & $10 \mathrm{~b}$ & $32 \mathrm{Aa}$ & $28 \mathrm{Aa}$ & 30 \\
\hline Médias & $19 \mathrm{~A}$ & $10 \mathrm{~B}$ & 15 & 20 & 19 & 20 \\
\hline
\end{tabular}

* Médias seguidas da mesma letra maiúscula na linha (para hidratação) e minúscula na coluna (para lotes), não diferem entre si pelo teste de Tukey a p > 0,5

$\mathrm{Na}$ avaliação de plântulas anormais (totais e deformadas) foi verificado menor porcentagem destas quando provenientes de sementes hidratadas, independente do lote avaliado (Tabela 4). Este resultado sugere que a técnica de hidratação favorece o crescimento das plântulas, permitindo a classificação destas em plântulas normais de acordo com o padrão estabelecido por Brasil (2009).

Em relação ao vigor, avaliado pela porcentagem de plântulas normais na primeira contagem, ou seja, aos sete dias após a instalação, foi constatado que as sementes dos lotes 2; 3; 4 e 5 submetidas à hidratação exibiram maior valor do que o das sementes não hidratadas (Tabela 4). Estes resultados foram parcialmente semelhantes ao do teste de germinação (Tabela 4). Quando os lotes foram comparados na ausência do tratamento de hidratação, foi observado maior porcentagem de plântulas normais na primeira contagem provenientes das sementes dos lotes 1; 2 e 4. Quando os lotes foram comparados na presença do tratamento de hidratação, foi verificado maior porcentagem de plântulas normais na primeira provenientes de sementes do lote 4 . Estes resultados foram semelhantes aos observados para germinação (Tabela 4).

Também, o vigor avaliado pelo teste de índice de velocidade de emergência variou em função da interação entre lotes avaliados e os tratamentos aos quais as sementes foram submetidas (Tabela 5). A hidratação favoreceu o comprimento de plântulas (total, da raiz primária e do hipocótilo), a massa de matéria seca, bem como a porcentagem de emergência de plântulas, independente do lote (Tabela 6). Também este tratamento favoreceu o índice de velocidade de emergência de plântulas provenientes dos lotes 2 e 3 (Tabela 6), diferindo parcialmente dos resultados do teste de germinação (Tabela 4). Em girassol, Hussain et al. (2006) verificaram que a imersão de sementes durante 24 horas a $27{ }^{\circ} \mathrm{C}$ seguida de secagem promoveu aumento na velocidade de emergência das plântulas em condições de campo. Em brássicas, a imersão em água por 32 horas seguida de secagem reduziu o tempo médio para a germinação de sementes de couvede-bruxelas e couve flor, que foram envelhecidas ou não 
Tabela 5 - Resumo da análise de variância para os dados de comprimento total de plântulas (CT); comprimento de raiz primária (CR); comprimento de hipocótilo (CH); massa seca (MS), índice de velocidade de emergência (IVE) e porcentagem final de emergência de plântulas (PE) de pinhão manso após terem sido ou não submetidas à técnica de hidratação por imersão em água

\begin{tabular}{lccccccc}
\hline \multirow{2}{*}{ Fontes de variação } & \multirow{2}{*}{ GL } & \multicolumn{7}{c}{ Quadrados Médios } \\
\cline { 3 - 8 } & & CT & CR & CH & MS & IVE & PE \\
\hline Lotes (L) & 4 & $3,723^{* *}$ & $1,629^{* *}$ & $1,834^{* *}$ & $0,199^{* *}$ & $0,249^{* *}$ & $3,146^{* *}$ \\
Hidratação(H) & 1 & $4,769^{* *}$ & $2,771^{* *}$ & $1,659^{* *}$ & $0,104^{* *}$ & $0,042^{\text {ns }}$ & $4,372^{* *}$ \\
L x H & 4 & $0,121^{\text {ns }}$ & $0,152^{\text {ns }}$ & $0,047^{\text {ns }}$ & $0,008^{\text {ns }}$ & $0,073^{*}$ & $1,287^{\text {ns }}$ \\
Erro & 30 & 0,204 & 0,081 & 0,148 & 0,011 & 0,020 & 0,565 \\
C. V. $(\%)$ & & 13,13 & 11,27 & 15,19 & 7,44 & 6,38 & 8,58 \\
\hline
\end{tabular}

${ }^{\mathrm{ns}}$-não significativo, ${ }^{*}$-significativo a $5 \%$ pelo teste $\mathrm{F}$ e $* *$ - significativo a $1 \%$ pelo teste $\mathrm{F}$

Tabela 6 - Dados médios de comprimento de plântulas (total, da raiz primária e do hipocótilo), de índice de velocidade de emergência e de emergência de plântulas, obtidos de cinco lotes de sementes pinhão manso após terem sido ou não submetidas à técnica de hidratação por imersão em água

\begin{tabular}{|c|c|c|c|c|c|c|}
\hline \multirow{2}{*}{ Lotes } & Sem hidratação & Com hidratação & Médias & Sem hidratação & Com hidratação & Médias \\
\hline & \multicolumn{3}{|c|}{ Comprimento total $(\mathrm{cm})$} & \multicolumn{3}{|c|}{ Raiz primária $(\mathrm{cm})$} \\
\hline 1 & 11,51 & 15,85 & $13,68 \mathrm{a}$ & 4,84 & 8,58 & $6,71 \mathrm{ab}$ \\
\hline 2 & 15,80 & 18,34 & 17,07 a & 8,75 & 9,01 & $8,88 \mathrm{a}$ \\
\hline 3 & 4,51 & 10,05 & $7,28 \mathrm{~b}$ & 2,25 & 5,25 & $3,75 \mathrm{c}$ \\
\hline 4 & 9,87 & 16,23 & $13,04 \mathrm{a}$ & 4,20 & 7,90 & $6,05 \mathrm{~b}$ \\
\hline 5 & 4,38 & 8,77 & $6,57 \mathrm{~b}$ & 2,24 & 4,61 & $3,42 \mathrm{c}$ \\
\hline \multirow[t]{2}{*}{ Médias } & $9,21 \mathrm{~B}$ & $13,84 \mathrm{~A}$ & & $4,45 \mathrm{~B}$ & $7,07 \mathrm{~A}$ & \\
\hline & \multicolumn{3}{|c|}{ Hipocótilo $(\mathrm{cm})$} & \multicolumn{3}{|c|}{ Massa seca $(\mathrm{mg})$} \\
\hline 1 & 6,68 & 7,28 & 6,98 a & 1,26 & 1,57 & $1,41 \mathrm{a}$ \\
\hline 2 & 7,05 & 9,33 & 8,19 a & 1,51 & 1,65 & $1,58 \mathrm{a}$ \\
\hline 3 & 2,26 & 4,80 & $3,53 \mathrm{~b}$ & 0,42 & 0,73 & $0,57 \mathrm{~b}$ \\
\hline 4 & 5,67 & 8,33 & $7,00 \mathrm{a}$ & 1,16 & 1,29 & $1,23 \mathrm{a}$ \\
\hline 5 & 2,14 & 4,16 & $3,15 b$ & 0,43 & 0,97 & $0,70 \mathrm{~b}$ \\
\hline \multirow[t]{2}{*}{ Médias } & $4,76 \mathrm{~B}$ & $6,78 \mathrm{~A}$ & & $0,95 \mathrm{~B}$ & $1,24 \mathrm{~A}$ & \\
\hline & \multicolumn{3}{|c|}{ Índice de velocidade de emergência } & \multicolumn{3}{|c|}{ Emergência de plântulas (\%) } \\
\hline 1 & $4,14 \mathrm{Ab}$ & $3,95 \mathrm{Abc}$ & 4,05 & 67 & 79 & $73 b$ \\
\hline 2 & $3,21 \mathrm{Bbc}$ & $4,70 \mathrm{Ab}$ & 3,96 & 62 & 93 & $77 \mathrm{ab}$ \\
\hline 3 & $2,60 \mathrm{Bc}$ & $3,26 \mathrm{Ac}$ & 2,93 & 59 & 71 & $65 b$ \\
\hline 4 & $5,10 \mathrm{Aa}$ & $5,17 \mathrm{Aa}$ & 5,14 & 90 & 100 & $95 \mathrm{a}$ \\
\hline 5 & 4,24 Aab & 3,64 Abc & 3,94 & 77 & 71 & $74 b$ \\
\hline Médias & 3,86 & 4,14 & & $71 \mathrm{~B}$ & $83 \mathrm{~A}$ & \\
\hline
\end{tabular}

*Médias seguidas da mesma letra maiúscula na linha (para hidratação) e minúscula na coluna (para lotes), não diferem entre si pelo teste de Tukey a p >0,5

artificialmente (THORNTON; POWELL, 1995). Na Tabela 6, também foi verificado que quando os lotes foram comparados na presença da hidratação, este tratamento propiciou maior índice de velocidade de emergência de plântulas provenientes do lote 4 . No entanto, quando não foi realizada a hidratação, as sementes dos lotes 4 e 5 apresntaram maior índie e velocidade de emergência (Tabela 6).

Foi constatada maior porcentagem de emergência das lântulas provenientes das sementes dos lotes 1; 3 e 5, 
que foram hidratadas do que as não hidratadas (Tabela 7). Este resultado do lote 5 é semelhante ao apresentado para emergência de plântulas em areia (Tabela. 6). Assim, constatou-se melhor desempenho dos lotes $1 ; 3$ e 5 , com qualidade fisiológica inferior a dos lotes 2 e 4 (Tabela 4), ou seja, em condições de casa de vegetação, a hidratação atenuou as diferenças no desempenho das sementes que compõem os lotes $1 ; 3$ e 5 que germinaram mais lentamente, acarretando diminuição do desenvolvimento das plantas (Tabela 4). Este tratamento de hidratação, que é uma das técnicas de condicionamento fisiológico pode favorecer a sincronização do processo de germinação de sementes, além de permitir menor exposição das sementes e plântulas a fatores adversos do ambiente, tais como aumento de temperatura e deficiência hídrica do substrato (MARCOS FILHO, 2005). Outro aspecto a abordar é que estes lotes provavelmente apresentavam qualidade intermediária, sendo possível encontrar resultados favoráveis da aplicação da hidratação para os mesmos. Para Marcos Filho (2005), as técnicas de condicionamento fisiológico pouco beneficiam lotes de baixo ou de alto vigor. Em relação à comparação dos lotes em cada tratamento, tanto com ou sem tratamento de hidratação, foi constatado que a maior porcentagem de emergência de plântulas foi proveniente das sementes do lote 4 (Tabela 6).

O número de folhas de pinhão manso variou em função da interação entre os lotes avaliados, os tratamentos de hidratação e os período de avaliação (Tabela 8). Quando foi realizado o tratamento de hidratação, ocorreu aumento do número de folhas das plantas obtidas de sementes do lote 5 , tanto aos 20 como aos 30 dias após a instalação (Tabela 9). Comparando-se os lotes após o tratamento de hidratação, na avaliação aos 20 dias, foi observado

Tabela 7 - Dados médios de porcentagem de emergência de plântulas (sobrevivência) em casa de vegetação, obtidos de cinco lotes de sementes de pinhão manso após terem sido ou não submetidas à técnica de hidratação por imersão em água

\begin{tabular}{cccc}
\hline Lotes & Sem hidratação $(\%)$ & Com hidratação (\%) & Médias \\
\hline 1 & $55 \mathrm{Bc}^{*}$ & $80 \mathrm{Ab}$ & 68 \\
2 & $65 \mathrm{Ab}$ & $70 \mathrm{Ac}$ & 68 \\
3 & $45 \mathrm{Bd}$ & $55 \mathrm{Ad}$ & 50 \\
4 & $85 \mathrm{Aa}$ & $90 \mathrm{Aa}$ & 88 \\
5 & $55 \mathrm{Bc}$ & $70 \mathrm{Ac}$ & 63 \\
Médias & 61 & 73 & \\
C.V. $(\%)$ & 2,46 & & \\
\hline
\end{tabular}

*Médias seguidas da mesma letra maiúscula na linha (com e sem pré-hidratação) e minúscula na coluna (para lotes), não diferem entre si pelo teste de Tukey a $\mathrm{p}>0,5$

Tabela 8 - Resumo da análise de variância para os dados de altura, caule e folhas de mudas provenientes de sementes de pinhão manso, após terem sido ou não submetidas à técnica de hidratação por imersão em água, com avaliações aos 10; 20; 30 e 40 dias após a semeadura

\begin{tabular}{lcccc}
\hline \multirow{2}{*}{ Fontes de variação } & GL & \multicolumn{3}{c}{ Quadrados Médios } \\
\cline { 3 - 4 } & & Altura & Caule & $0,205^{* *}$ \\
\hline Lotes $(\mathrm{L})$ & 4 & $0,033^{\mathrm{ns}}$ & $0,013^{\mathrm{ns}}$ & $0,057^{\mathrm{ns}}$ \\
Hidratação (H) & 1 & $0,010^{\mathrm{ns}}$ & $0,001^{\mathrm{ns}}$ & $18,953^{* *}$ \\
Período (P) & 3 & $87,004^{* *}$ & $1,326^{* *}$ & $0,062^{\mathrm{ns}}$ \\
$\mathrm{L} * \mathrm{H}$ & 4 & $0,285^{\mathrm{ns}}$ & $0,004^{\mathrm{ns}}$ & $0,139^{* *}$ \\
$\mathrm{~L}^{*} \mathrm{P}$ & 12 & $0,039^{\mathrm{ns}}$ & $0,002^{\mathrm{ns}}$ & $0,088^{\mathrm{ns}}$ \\
$\mathrm{H} * \mathrm{P}$ & 3 & $0,020^{\mathrm{ns}}$ & $0,005^{\mathrm{ns}}$ & $0,102^{*}$ \\
$\mathrm{~L}^{*} \mathrm{H} * \mathrm{P}$ & 12 & $0,065^{\mathrm{ns}}$ & $0,003^{\mathrm{ns}}$ & 0,053 \\
Resíduo & 120 & 0,129 & 0,002 & 9,20 \\
C.V. $(\%)$ & & 8,19 & 3,73 & \\
\hline
\end{tabular}

ns- não significativo, *- significativo a $5 \%$ pelo teste $\mathrm{Fe}{ }^{* *}$ - significativo a $1 \%$ pelo teste $\mathrm{F}$ 
Tabela 9 - Dados médios de altura, diâmetro de caule e número de folhas das plantas, obtidos de cinco lotes (1, 2, 3, 4 e 5) de sementes de pinhão manso, com $(\mathrm{C} / \mathrm{H})$ ou sem pré-hidratação $(\mathrm{S} / \mathrm{H})$. Avaliação aos 10, 20, 30 e 40 dias após a instalação

\begin{tabular}{|c|c|c|c|c|c|c|c|c|c|}
\hline \multirow{2}{*}{ Lotes } & \multicolumn{3}{|c|}{ Altura $(\mathrm{cm})$} & \multicolumn{3}{|c|}{ Caule $(\mathrm{cm})$} & \multicolumn{3}{|c|}{ Número de Folhas } \\
\hline & $\mathrm{S} / \mathrm{H}$ & $\mathrm{C} / \mathrm{H}$ & Médias & $\mathrm{S} / \mathrm{H}$ & $\mathrm{C} / \mathrm{H}$ & Médias & $\mathrm{S} / \mathrm{H}$ & $\mathrm{C} / \mathrm{H}$ & Médias \\
\hline \multicolumn{10}{|c|}{10 DAS } \\
\hline 1 & 12,0 & 11,3 & $11,6 \mathrm{a}$ & 0,5 & 0,5 & $0,5 \mathrm{a}$ & 2,8 & 2,6 & $2,70 \mathrm{a}$ \\
\hline 2 & 11,1 & 12,2 & $11,6 \mathrm{a}$ & 0,5 & 0,5 & $0,5 \mathrm{a}$ & 2,5 & 2,9 & $2,70 \mathrm{a}$ \\
\hline 3 & 11,2 & 11,6 & $11,4 \mathrm{a}$ & 0,5 & 0,5 & $0,5 \mathrm{a}$ & 2,7 & 3,1 & $2,90 \mathrm{a}$ \\
\hline 4 & 11,1 & 12,1 & $11,6 \mathrm{a}$ & 0,5 & 0,5 & $0,5 \mathrm{a}$ & 2,7 & 3,0 & $2,85 \mathrm{a}$ \\
\hline 5 & 12,0 & 11,5 & $11,7 \mathrm{a}$ & 0,5 & 0,5 & $0,5 \mathrm{a}$ & 3,0 & 2,2 & $2,60 \mathrm{a}$ \\
\hline Médias & $11,4 \mathrm{~A}^{*}$ & $11,7 \mathrm{~A}$ & & $0,5 \mathrm{a}$ & $0,5 \mathrm{~A}$ & & $2,7 \mathrm{~A}$ & $2,7 \mathrm{~A}$ & \\
\hline \multicolumn{10}{|c|}{$20 \mathrm{DAS}$} \\
\hline 1 & 12,8 & 11,7 & $12,2 \mathrm{a}$ & 0,7 & 0,7 & $0,70 \mathrm{a}$ & $5,1 \mathrm{Aa}$ & $5,2 \mathrm{Aab}$ & 5,10 \\
\hline 2 & 11,8 & 12,5 & $12,1 \mathrm{a}$ & 0,7 & 0,8 & $0,75 \mathrm{a}$ & 4,4 Aa & $4,8 \mathrm{Ab}$ & 4,60 \\
\hline 3 & 12,1 & 12,7 & $12,4 \mathrm{a}$ & 0,6 & 0,7 & $0,65 \mathrm{a}$ & 5,6 Aa & 5,3 Aab & 5,45 \\
\hline 4 & 11,8 & 12,4 & $12,1 \mathrm{a}$ & 0,6 & 0,8 & $0,70 \mathrm{a}$ & 4,3 Aa & $5,0 \mathrm{Ab}$ & 4,65 \\
\hline 5 & 12,7 & 12,1 & $12,4 \mathrm{a}$ & 0,8 & 0,7 & $0,75 \mathrm{a}$ & $5,1 \mathrm{Ba}$ & 6,3 Aa & 5,70 \\
\hline Médias & $12,2 \mathrm{~A}$ & $12,2 \mathrm{~A}$ & & $0,6 \mathrm{a}$ & $0,7 \mathrm{~A}$ & & 4,9 & 5,32 & \\
\hline \multicolumn{10}{|c|}{$30 \mathrm{DAS}$} \\
\hline 1 & 24,5 & 25,0 & $24,7 \mathrm{a}$ & $0,9 \mathrm{a}$ & 0,9 & $0,9 \mathrm{a}$ & $6,1 \mathrm{Aa}$ & $5,5 \mathrm{Ab}$ & 5,80 \\
\hline 2 & 23,8 & 26,1 & $24,9 \mathrm{a}$ & $0,9 \mathrm{a}$ & 1,0 & $0,9 \mathrm{a}$ & 7,5 Aa & 6,5 Aab & 7,00 \\
\hline 3 & 25,0 & 26,9 & $25,9 \mathrm{a}$ & $0,7 \mathrm{a}$ & 0,8 & $0,7 \mathrm{a}$ & $6,5 \mathrm{Aa}$ & $6,3 \mathrm{Ab}$ & 6,40 \\
\hline 4 & 25,4 & 24,7 & $25,0 \mathrm{a}$ & $0,8 \mathrm{a}$ & 0,9 & $0,8 \mathrm{a}$ & $5,9 \mathrm{Aa}$ & $5,8 \mathrm{Ab}$ & 5,85 \\
\hline 5 & 26,5 & 23,9 & $25,2 \mathrm{a}$ & $1,0 \mathrm{a}$ & 0,9 & $0,9 \mathrm{a}$ & $6,4 \mathrm{Ba}$ & 7,6 Aa & 7,00 \\
\hline Médias & $25,0 \mathrm{~A}$ & $25,3 \mathrm{~A}$ & & $0,8 \mathrm{a}$ & $0,9 \mathrm{~A}$ & & 6,4 & 6,3 & \\
\hline \multicolumn{10}{|c|}{$40 \mathrm{DAS}$} \\
\hline 1 & 28,7 & 28,2 & $28,4 \mathrm{a}$ & 1,3 & 1,3 & $1,30 \mathrm{a}$ & 7,4 & 7,6 & $7,50 \mathrm{a}$ \\
\hline 2 & 25,1 & 29,3 & $27,2 \mathrm{a}$ & 1,3 & 1,2 & $1,25 \mathrm{a}$ & 8,1 & 8,4 & $8,20 \mathrm{a}$ \\
\hline 3 & 27,4 & 29,7 & $28,5 \mathrm{a}$ & 1,3 & 1,2 & $1,25 \mathrm{a}$ & 7,9 & 8,2 & $8,05 \mathrm{a}$ \\
\hline 4 & 28,9 & 26,1 & $27,5 \mathrm{a}$ & 1,3 & 1,2 & $1,25 \mathrm{a}$ & 7,3 & 7,1 & $7,20 \mathrm{a}$ \\
\hline 5 & 30,8 & 26,6 & $28,7 \mathrm{a}$ & 1,3 & 1,2 & $1,25 \mathrm{a}$ & 8,0 & 8,0 & $8,00 \mathrm{a}$ \\
\hline Médias & $28,1 \mathrm{~A}$ & $27,9 \mathrm{~A}$ & & $1,3 \mathrm{~A}$ & $1,22 \mathrm{~A}$ & & 7,74 A & $7,86 \mathrm{~A}$ & \\
\hline
\end{tabular}

*Médias seguidas da mesma letra maiúscula na linha (com e sem hidratação) e minúscula na coluna (para lotes), não diferem entre si pelo teste de Tukey a $\mathrm{p}>0,5$

maior número de folhas nas plantas provenientes das sementes dos lotes $1 ; 3$ e 5 . Também aos 30 dias, na mesma situação, as plantas provenientes dos lotes 2 e 5 apresentaram o maior valor (Tabela 9). Assim, as plantas provenientes das sementes que foram hidratadas podem ser beneficiadas quanto ao seu crescimento e uniformidade. Também em girassol, Farooq et al. (2007), esta técnica de condicionamento fisiológico promoveu maior crescimento e desenvolvimento das plântulas. Além disso, de acordo com Finch-Savage e Mchee (1990), esta vantagem determina a elevação da taxa de repicagem, acelera a rotatividade de produção e conseqüentemente o retorno financeiro.

\section{CONCLUSÕES}

1. A hidratação promoveu o aumento do comprimento e da massa seca de plântulas e favoreceu a emergência de plântulas em areia; 
2. A sobrevivência das plantas provenientes apenas de sementes de qualidade fisiológica intermediária foi beneficiada pela hidratação.

\section{AGRADECIMENTOS}

Os autores agradecem a concessão de bolsas provenientes do programa REUNI, CAPES e CNPq, respectivamente.

\section{REFERÊNCIAS}

BAILLY, C. et al. Changes in activities of antioxidant enzymes and lipoxygenase during growth of sunflower seedlings from seeds of different vigour. Seed Science Research, v. 12, n. 01, p. $47-55,2002$.

BARROS, C. S.; ROSSETTO, C. A. V. Condicionamento fisiológico de aquênios de girassol. Ciência Rural, v. 39, n. 06, p. 1667-1675, 2009.

BEJANDI, T. K. et al. Seed priming and sulfur effects on soybean cell membrane stability and yield in saline soil. Pesquisa Agropecuária Brasileira, v. 44, n. 08, p. 1114-1117, 2009.

BORTOLLOTTO, R. P. et al. Comportamento de hidratação e qualidade fisiológica das sementes de arroz. Bragantia, v. 67, n. 04, p. 991-996, 2008.

BEWLEY, J. D.; BLACK, M. Seeds: physiology of development and germination. 2. ed. New York: Plenum Press, 1994. 445 p.

BRASIL. Instrução normativa n. 25, de 16 de Dezembro de 2005. Disponível em: <http://www.agricultura.gov.br> Acesso em: 06 out. 2009.

BRASIL. Ministério da Agricultura e Reforma Agrária. Regras para Análise de Sementes. Brasília: SNDA/DNDV/ CLAV, 2009. Disponível em: <http://www.agricultura.gov. br> Acesso em: 28 fev. 2011.

BRAZ, M. R. S.; ROSSETTO, C. A. V. Condicionamento fisiológico na germinação e no vigor de sementes armazenadas de café. Ciência Rural, v. 39, n. 01, p. 1849-1856, 2008.

CASEIRO, R. F.; BENNETT, M. A.; MARCOS FILHO, J. Comparison of three priming techniques for onion seed lots differing in initial seed quality. Seed Science and Technology, v. 32, n. 02, p. 365-375, 2004.

CHAVES, L. H. G. et al. Zinco e cobre em pinhão manso. Revista Caatinga, v. 22, n. 03, p. 94-99, 2009.

CONSENÇO, G. et al. Sulfentrazole e a qualidade fisiológica das sementes de girassol. Revista Brasileira de Agrociência, v. 13, n. 01, p. 109-113, 2007.

DRUMOND, M. A. Desempenho agronomico de genótipos de pinhão manso no semi árido pernambucano. Ciência Rural, v. 40, n. 01, p. 44-47, 2010.
FAROOQ, M. et. al. Comparative efficacy of surface drying and re-drying seed priming in rice: changes in emergence, seedling growth and associated metabolic events. Paddy Water Environmental, v. 08, n. 01, p. 15-22, 2010.

FAROOQ, M. et al. Incorporation of polyamines in the priming media enhances the germination and early seedling growth in hybrid sunflower (Helianthus annuus L.) International Journal of Agriculture \& Biology, v. 09, n. 06, p. 868-872, 2007.

FINCH-SAVAGE, W .E.; McKEE, J. M. T. The influence of seed quality and pre-germination treatment on cauliflower and cabbage transplant production and filed growth. Annals of Applied Biology, v. 116, n. 02, p. 365-369, 1990.

FUJIKURA, Y. et al. Hydropriming, a simple and inexpensive priming method. Seed Science and Technology, v. 21, n. 03, p. 639-642, 1993.

GHASSEMI-GOLEZANI, K. et al. Effects of hydro-priming duration on seedling vigour and grain yield of pinto bean (Phaseolus vulgaris L.) Cultivars. Notulae Botanicae Horti Agrobotanici Cluj-Napoca, v. 38, n. 01, p. 109-113, 2010.

GIURIZATTO, M. I. K. et al. Qualidade fisiológica de sementes de soja submetidas ao hidrocondicionamento. Acta Scientiarum Agronomy, v. 30, n. 05, p. 711-717, 2008.

HARRIS, D. et al. On-farm seed priming: using participatory methods to revive and refine a key technology. Agricultural Systems, v. 69, n 01/02, p. 151-164, 2001.

HUSSAIN, M. et al. Influence of seed priming techniques on the seedling establishment, yield and quality of hibrid sunflower. International Journal of Agriculture and Biology, v. 08, n. 01, p. 14-18, 2006.

MARCOS FILHO, J. Fisiologia de sementes de plantas cultivadas. Piracicaba: FEALQ, 2005. 495 p.

NAKAGAWA, J. Testes de vigor baseados no desempenho das plântulas. In: VIEIRA, R. D.; CARVALHO, N. M. Testes de vigor em sementes. Jaboticabal: FUNEP, 1994.

PINTO, T. L. F. et al. Avaliação da viabilidade de sementes de pinhão manso pelos testes de tetrazólio e de raios X. Revista Brasileira de Sementes, v. 31, n. 02, p. 195-2001, 2009.

RIBEIRO, V. P. et al. Determinação do potencial osmótico e do período de embebição utilizados no condicionamento fisiológico de sementes de algodão. Ciência \& Agrotecnologia, v. 26, n. 05, p. 911-917, 2002.

ROSSETTO, C. A. V. et al. Efeito da disponibilidade hídrica do substrato, da qualidade fisiológica e do teor de água inicial das sementes de soja no processo de germinação. Scientia Agricola, v. 54, n. 01/02, p. 97-105, 1997.

SANCHEZ, J. A.; ORTA, R.; MUNOZ, B. C. Tratamientos pregerminativos de hidratacion deshidratacion de las semillas y sus efectos en plantas de interes agricola. Agronomia Costarricense, v. 25, n. 01, p. 67-92, 2001.

THORNTON, J. M.; POWELL, A. A. Prolonged aerated hydration for the improvement of seed quality in Brassica oleracea L. Annals of Applied Biology, v. 127,n. 01/02, p. 183-189, 1995. 
Este artigo sofreu alterações por solicitação do editor em Jun/2012 conforme ERRATA abaixo:

Página (s)

589

590-592-594-596
Onde se lê

Nathalia Braga da Silva

N. B. Silva et al.
Leia-se

Nathália da Silva Braga

N. S. Braga et al. 